\title{
The Study of Late Post Operative Complications (Pco) Following Small Incision Cataract Surgery with Square Edged Rigid/ Foldable Intraocular Lens Implantation
}

\author{
Dr.Jeyalatha $\mathrm{D}^{1}$,Dr.Beena $\mathrm{R}^{2}$,Dr.Samarapuri ${ }^{2^{*}}$ \\ $\left({ }^{1,2}\right.$ Assistant Professor, Dept Of Ophthalmology, Kanyakumari Govt Medical College, Asaripallam, K.K. \\ District, Dr.MGR Medical University, Chennai, India \\ ${ }^{2 *}$ Associate Professor, Dept Of Ophthalmology, Kanyakumari Govt Medical College, Asaripallam, K.K. \\ District, Dr.MGR Medical University, Chennai, India)
}

\begin{abstract}
Background: $P C O$ is one of the most common complication of cataract surgery and there is a primary need to reduce its incidence. Treatment with Neodymium:YAG (Nd: YAG) laser posterior capsulotomy is expensive and associated with significant morbidity in the identified patients. Improvements in surgical technique and IOL related factors like material and design definitely influences the PCO development and its incidence.

Aim and objective: The assesment of visual outcome and posterior capsular opacification in 750 eyes of 700 patients operated for cataract surgery - SICS with PCIOL implantation. Also early identification of complications, timely intervention \& management to ensure quality vision.

Material and Methods: The study is a retrospective study which involves the assesment of visual outcome \& various post operative complications in 750 eyes of 700 patients operated for cataract surgery( SICS with PCIOL implantation) in the department of ophthalmology in KGMCH, Asaripallam during Febravary 2016 to May 2016. Patients attending our hospital out patient department \& also through camps in kanyakumari district are recruited.

Results: The various post operative complications following Rigid/ Foldable IOL implantation are hyphaema, cornealedema/ striate keratopathy, intraocular pressure rise, cystoids macular edema, bullous keratopathy. Among patients with rigid IOL $11 \%$ developed the post operative complications where as in patients with foldable IOL 4\% developed the complications. PCO developing later after 6 months period is found to be the most common cause for defective vision.

Conclusion: The modern surgical techniques, IOL optic design and lens material are the important factors in reducing the incidence of $P C O$.
\end{abstract}

Keywords: visual acuity, SICS, intraocular lens, PCO, Laser treatment

\section{Introduction}

Cataract is the leading cause of avoidable blindness in India and cataract surgery forms the major workload of most ophthalmic units in the country. In India cataract is considered to be the cause for $50 \%$ of the total blind population of 150 million. The WHO estimates that cataract blindness will reach 40 million by 2020. The WHO proposes that between 2000 and 2020, the number of cataract surgeries performed worldwide have to be tripled to keep in pace with the needs of the population. Manual small incision cataract surgery (MSICS) is a very popular, widely practiced and most economical cataract surgery than Phaco surgery which needs expensive equipment like phacoemulsification unit. In developing countries like India, Posterior Capsular Opacification (PCO) continues to be the most common complication after a successful PCIOL implantation. Incidence of PCO is known to have multifactorial pathogenesis like capsulorrhexios, IOL design as rigid PMMA / Acrylic foldable biconvex aspheric optic with 360 degree square edge. PCO causes diminished visual acuity, glare, impaired contrast sensitivity function thus affecting the functional recovery of the operated eye.

The aim of our study is the assesment of posterior capsular opacification in 750 eyes of 700 patients operated for cataract surgery (SICS with PC IOL implantation) in the department of ophthalmology. Henceforth our study has been undertaken with the objective of giving good quality visual standards in addition to quantitative vision.

\section{Materials And Methods}

The study is a retrospective study which involves the assesment of visual outcome \& various post operative complications in 750 eyes of 700 patients operated for cataract surgery (SICS with PCIOL 
implantation) in the department of ophthalmology in $\mathrm{KGMCH}$, Asaripallam. Patients attending the out patient department of our hospital \& also through camps in kanyakumari district are recruited for the study. Institutional Ethical committee approval is obtained and study conducted for a period of one year from February 2016 to May 2016.

Incluson Criteria: Patients who had good visual acuity prior to development of cataract were included in the study.

Exclusion Criteria: Patients with Corneal lesion , Retinal pathology, Glaucoma, Complicated cataract, Optic atrophy.Detailed history is taken as regards to any ocular trauma, any previous eye surgery or systemic diseases like DM, HT, COPD and IHD.

Patients are subjected to a detailed systemic and ocular examination. Pre operative investigations and done. Surgery is performed as follows:

* peribulbar anaesthesia using a mixture of $2 \%$ Lignocaine $\mathrm{HCl}$ and $0.75 \%$ Bupivacaine in the proportion of $75: 25$ respectively along with injectable Hyalase 25 units per ml of anaesthetic solution.

* By using a keratome of $2.8 \mathrm{~mm}$ a triplanar sclero corneal tunnel is made for a distance of $6 \mathrm{~mm}$.

* anterior capsule is stained with tryphan blue. 4-5 mm central curvilinear capsulorrhexis is made with 26 guage needle.

* Hydrodissection and hydrodelineation is done. Nucleus is delivered by manual method. Cortex is aspirated.

* Square edged rigid IOL is inserted in the bag in 375 eyes \& acrylic foldable IOL is inserted in the bag in 375 eyes. In both groups capsular polishing procedures are done

* Inj subconjunctival - Garamycin,Decadran $0.3 \mathrm{ml}$ given in all the eyes

* Per operative complication if any is noted

* Eye is patched for $24 \mathrm{hrs}$

* Post op regime of antibiotic with steroids, cycloplegic given for 6-8 weeks

Visual acuity is tested with correction on : 1st, 5th day, 3rd week, 6th week, every 3 months for one year post operative period. Statistical Analysis- results are tabulated in Microsoft Excel sheet and data is analysed with the Statistical Analysis System software package (SPSS).

\section{Results}

Table -1 : Distribution of participants by age \& sex

\begin{tabular}{|c|c|c|c|c|}
\hline \multirow{2}{*}{$\begin{array}{c}\text { Age } \\
\text { group(years) }\end{array}$} & \multicolumn{2}{|c|}{ Male } & \multicolumn{2}{c|}{ Female } \\
\cline { 2 - 5 } & Rigid & Foldable & Rigid & Foldable \\
\hline $50-60$ & 50 & 56 & 55 & 63 \\
\hline $61-70$ & 112 & 100 & 115 & 121 \\
\hline $71-80$ & 20 & 16 & 23 & 19 \\
\hline
\end{tabular}

Table - 2 : Visual Acuity of patients operated with Rigid IOL

\begin{tabular}{|c|c|c|c|}
\hline \multirow[t]{2}{*}{ Post operative period } & \multicolumn{3}{|c|}{ Rigid IOL (375) } \\
\hline & $\mathrm{VA}>6 / 18$ & $6 / 18$ to $6 / 60$ & $<6 / 60$ \\
\hline $1^{\text {st }} \mathrm{POD}$ & $262(70 \%)$ & $75(20 \%)$ & $37(10 \%)$ \\
\hline $1^{\text {st }}$ week & $300(80 \%)$ & $56(15 \%)$ & $19(5 \%)$ \\
\hline $6^{\text {th }}$ week & $337(90 \%)$ & $26(7 \%)$ & $12(3 \%)$ \\
\hline $6^{\text {th }}$ months & & $93(25 \%)$ & $20(5 \%)$ \\
\hline 1 year & & $150(40 \%)$ & $38(10 \%)$ \\
\hline
\end{tabular}

Table - 3 : Visual Acuity of patients operated with Foldable IOL

\begin{tabular}{|l|c|c|c|}
\hline \multirow{2}{*}{ Post operative period } & \multicolumn{3}{|c|}{ Foldable IOL (375) } \\
\cline { 2 - 4 } & VA>6/18 & $6 / 18$ to $6 / 60$ & $<6 / 60$ \\
\hline $1^{\text {st }}$ POD & $281(75 \%)$ & $56(15 \%)$ & $38(10 \%)$ \\
\hline $1^{\text {st }}$ eek & $318(85 \%)$ & $37(10 \%)$ & $20(5 \%)$ \\
\hline $6^{\text {th }}$ week & $345(92 \%)$ & $20(5 \%)$ & $10(3 \%)$ \\
\hline $6^{\text {th }}$ months & $318(85 \%)$ & $50(13 \%)$ & $7(2 \%)$ \\
\hline 1 year & $281(75 \%)$ & $86(23 \%)$ & $8(2 \%)$ \\
\hline
\end{tabular}

Table - 4: Post operative complications following Rigid/ Foldable IOL

\begin{tabular}{|l|c|c|}
\hline Post Operative Complication & Rigid IOL (375) & Foldable IOL(375) \\
\hline Hyphema & 5 & 4 \\
\hline Corneal edema/ Striate keratopathy & 10 & 6 \\
\hline Intraocular pressure rise & 10 & 5 \\
\hline Posterior capsular opacity & 15 & 5 \\
\hline
\end{tabular}


The Study Of Late Post Operative Complications (Pco) Following Small......

\begin{tabular}{|l|c|c|}
\hline Cystoid macular edema & 3 & 2 \\
\hline Bullous keratopathy & 1 & 0 \\
\hline Endophthalmitis & 0 & 0 \\
\hline Total & 44 & 22 \\
\hline Percentage & $11 \%$ & $6 \%$ \\
\hline
\end{tabular}

Table - 5 : Diminished Visual Acuity of eyes with PCO

\begin{tabular}{|l|c|c|c|c|c|c|}
\hline & \multicolumn{3}{|c|}{ Rigid (25) } & \multicolumn{3}{c|}{ Foldable (5) } \\
\cline { 2 - 7 } & VA>6/18 & $6 / 18$ to 6/60 & $<6 / 60$ & VA>6/18 & $\begin{array}{c}6 / 18 \text { to } \\
6 / 60\end{array}$ & $<6 / 60$ \\
\hline 6 weeks & - & - & & - & - & - \\
\hline 6 Months & - & - & 3 & - & - & 1 \\
\hline 1 year & - & - & 12 & - & - & 4 \\
\hline
\end{tabular}

Table 1. Out of 750 eyes operated, in the age group 50-60 years, rigid IOL was placed in 105 eyes ( male - 50, female - 55) and foldable IOL was placed in 119 eyes ( male - 56, females- 63). In the age group 61 to 70, rigid IOL was placed in 227 eyes ( male - 112, female - 115) and foldable IOL was placed 221 eyes ( male -100 , females- 121$)$. In the age group $70-80$ years, rigid IOL was placed in 43 eyes ( male -20 , female -23 ) and foldable IOL was placed in 35 eyes ( male -16 , females- 19).

Table 2\&3. BCVA following rigid IOL implantation at the end of 6 weeks, 6 months and one year is given as follows. At the end of 6 weeks, VA $>6 / 18$ is present in $90 \%$ of eyes and VA< $6 / 60$ is in $3 \%$ eyes, later at 6 months VA $>6 / 18$ is present in $70 \%$ and VA $<6 / 60$ is in $5 \%$ eyes, and at the end of 1 year VA $>6 / 18$ is present in 50\% and VA $<6 / 60$ is $10 \%$ of eyes. BCVA following foldable IOL implantation at various period is given as follows. At the end of 6 weeks, VA $>6 / 18$ is present in $92 \%$ of eyes and $\mathrm{VA}<6 / 60$ is in $3 \%$, later at 6 months $\mathrm{VA}>6 / 18$ is $85 \%$ and $\mathrm{VA}<6 / 60$ is $2 \%$ eyes, at the end of 1 year $\mathrm{VA}>6 / 18$ is $75 \%$ and $\mathrm{VA}<6 / 60$ is $2 \%$ of eyes.

Table 4. 375 eyes operated with rigid IOL developed various complications as hyphema, corneal edema / striate keratopathy, IOP rise, PCO, cystoid macular edema, bullous keratopathy accounting for a total $11 \%$. In 375 eyes operated with foldable IOL $6 \%$ developed the various complications.

Table 5. Among 375 eyes operated with rigid IOL $4 \%$ of them developed thick PCO after a period of 6 months with their visual acuity < 6/60. Among 375 eyes operated with foldable IOL, $1.3 \%$ of them developed thick PCO after a period of 6 months and visual acuity is found to be $<6 / 60$.

\section{Discussion}

Total of 375 eyes were implanted with foldable IOL and another 375 eyes with rigid IOL. Following IOL implantation, among eyes with visual impairment due to various post operative complications, the prevalence percentage is found to be more among those implanted with rigid than foldable IOL. Also marked deterioration of vision was noted after a period of 6 months in our study. Thick PCO the most common cause for defective vision, presenting during follow up at 6 months and one year period. The incidence of PCO is $1.3 \%$ in eyes with foldable IOL and $4 \%$ in eyes with rigid IOL.

Management of PCO with Nd Yag laser posterior capsulotomy can be associated with significant complications. Potential problems include IOL optic damage/ pitting, IOP elevation, cystoid macular edema, retinal detachment, IOL subluxation. ${ }^{1,2}$ PCO represents a significant cost to the health care system in USA $\mathrm{Nd}$ Yag laser treatment of 1 million patients per year cost upto 250 million dollars. ${ }^{3}$ A posterior capsulotomy can increase the risk of posterior segment complications in high myopes and patients with uveitis, glaucoma, and diabetic retinopathy. Finally a successful expansion of SICS with IOL surgery in the developing world depends on eradication, or at least reduction of PCO, since patient follow up is difficult and access to the $\mathrm{Nd}$ : Yag laser is not widely available. ${ }^{4}$ In our study visually significant PCO is noted in 5.3\% of patients having undergone SICS with PCIOL after one year similar findings reported by Mannalis $\mathrm{N}$ et al. ${ }^{5}$

Regarding the surgical technique, cortical cleaving hydrodissection of nucleus followed by its rotation during SICS results in removal of maximum lens fibers and epithelial cells at the equator of the capsular bag thereby reducing the chances of PCO. By freeing and rotating the lens nucleus, hydrodissection facilitates lens nucleus and cortex removal without zonular - capsular - rupture. ${ }^{6}$ Development of PCO is more dependant on the quality and thoroughness of surgical cortical clean up, especially equatorial lens cells and fibers thereby reducing the incidence of PCO formation.?

During placement of rigid IOL, in the bag fixation of rigid IOL occurs only about $60 \%$ of time during SICS procedure. In case one or both the haptics are not placed in the capsular bag, a potential space is created allowing avenue for cells to grow posteriorly towards the visual axis. With modern foldable IOL implantation, in the bag fixation has increased to $>90 \%$. In the bag placement of IOL in SICS creates a barrier effect of IOL which results in hindrance to migration of equatorial lens epithelial cells over 
posterior capsule. Nishi et al ${ }^{8}$ support a physiological barrier to cellular migration through the phenomenon of contact inhibition and this factor certainly plays a role in prevention of PCO. Continuous curvilinear capsulorehxis of anterior capsule of moderate diameter just overlapping the optic which was done in cases of SICS creates a barrier effect for formation of PCO by a shrink wrap effect ${ }^{9}$

\section{Conclusion}

The findings of the present study indicate that posterior capsule opacification is one of the common complication of cataract surgery which can be minimized by the technique of small incision cataract surgery and phacoemulsification. This is probably due to three important steps being followed in both the techniques like continuous curvilinear capsulorrhexis, hydrodissection and in -the -bag placement of IOL. The intraocular implantation of foldable IOL helps to reduce the incidence of PCO to a greater extent as compared to the rigid IOL. Thus modern surgical techniques, IOL optic design and lens material are important factors in reducing the incidence of PCO to ensure the best post operative visual outcome and quality of life.

\section{References}

[1]. HolwegerRR, MarefatB. Intraocular pressure change after neodymium G capsulotomy. J Cataract Refract Surg 1997;23:11521.

[2]. Sundelin K, Sjostrand J.Posterior capsule opacificatin 5 years after extracapsular cataract extraction. 1999;25(2):246-250

[3]. Apple DJ, Solomon KD, Tetz MR, Assia EI, Holland EY, Legler UF, et al. Posterior capsule opacification. Surv Ophthalmol 1992;37:73-116.

[4]. Apple DJ, Ram J, Foster A, Peng Q. Elimination of cataract blindness: A global perspective entering the new millennium. Surv Ophthalmol 2000;45:S70-S99.

[5]. Mannalis N, Crandall AS, Linebayer E, et al. Effect of intraocularlens size on posterior capsule opacification after phacoemulsification. J Cataract Refract Surg 1995; 21: 99-102.

[6]. Ram J, Pandey SK, Apple DJ, et al. Effect of in-the-bag intraocular lens fixation on the prevention of posterior opacification. J Cataract Refract Surg 2001; $27 ; 1039-46$.

[7]. Ram J, Apple DJ, Peng Q, et al. Update on fixation of rigid andfoldable posterior chamber intraocular lenses. Part II: Choosingthe correct haptic fixation and intraocular lens design to helperadicate PCO. Ophthalmology 1999; 106: 891-900.

[8]. Nishi O, Nishi K. Preventing posterior capsule opacification by creating a discontinuous sharp bend in the capsule. J Cataract Refract Surg 1999; 29: 587-94.

[9]. Smith S, Daynes T, Hinckley M, et al. The effect of lens edgedesign versus anterior capsule overlap on posterior capsule opacification. Am J Ophthalmol $2004 ; 138: 521-6$.

\section{Tunnel Incision}

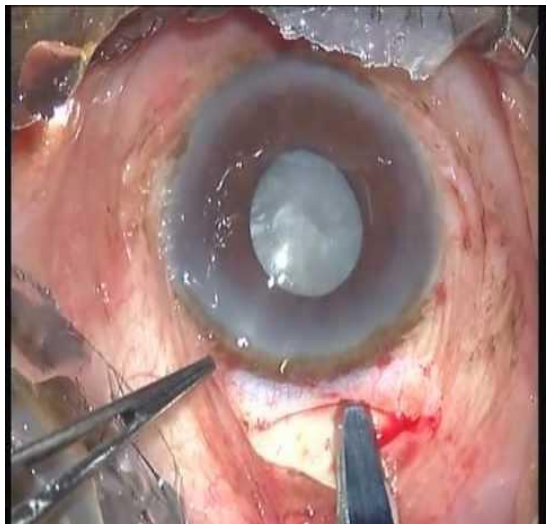

Nucleus Rotation

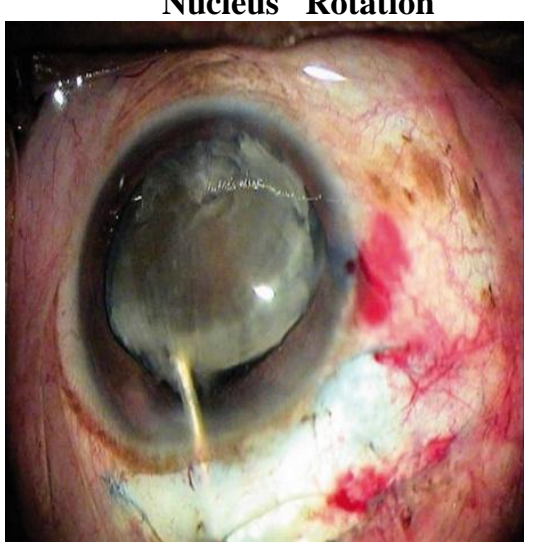

\section{Hydrodissection}

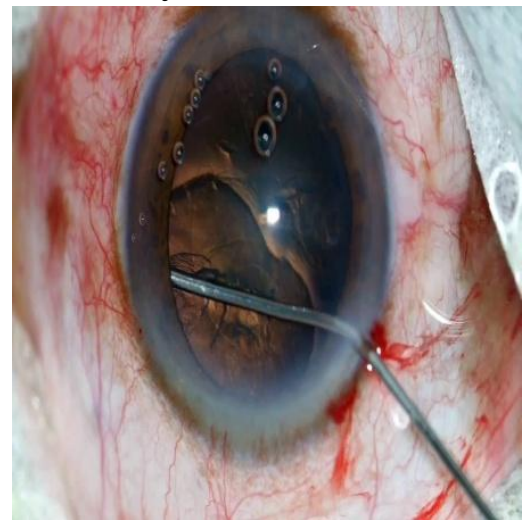

Iol Implantation

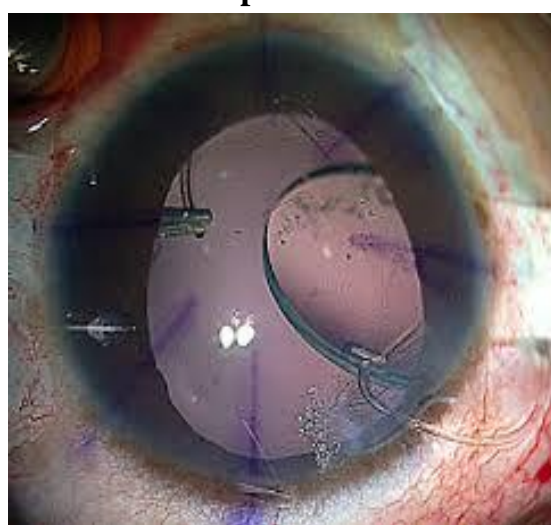

